\title{
Applying science in practice: the optimization of biological therapy in rheumatoid arthritis
}

\author{
Sofia Ramiro ${ }^{\dagger 1-3}$, Pedro Machado ${ }^{\dagger, 5}$, Jasvinder A Singh ${ }^{6}$, Robert B Landewé1,2 and José António P da Silva*4
}

\begin{abstract}
Most authorities recommend starting biological agents upon failure of at least one disease-modifying agent in patients with rheumatoid arthritis. However, owing to the absence of head-to-head studies, there is little guidance about which biological to select. Still, the practicing clinician has to decide. This review explores the application of published evidence to practice, discussing the goals of treatment, the (in) ability to predict individual responses to therapy, and the potential value of indirect comparisons. We suggest that cycling of biological agents, until remission is achieved or until the most effective agent for that individual patient is determined, deserves consideration in the current stage of knowledge.
\end{abstract}

\section{Introduction}

The development of specific biological therapies has resulted in a remarkable improvement in the treatment of rheumatoid arthritis (RA) and also in the understanding of its complex pathogenesis. We better recognize the multitude of cells and biological pathways involved in the disease process. We have also become more aware of the individual variability in disease features and in patterns of response to therapy. A large array of new treatment opportunities is currently under development and soon will be available as new biological agents. While enjoying these fruits of research, rheumatologists face the challenge of defining the best therapeutic plan for patients who have failed classical disease-modifying antirheumatic drugs (DMARDs).

\section{Remission is now a realistic therapeutic goal in every patient}

It is certainly desirable that our patients feel better and have improved function and acute-phase reactants as

\footnotetext{
${ }^{\dagger}$ Contributed equally.

*Correspondence: jdasilva@huc.min-saude.pt

${ }^{4}$ Department of Rheumatology, Hospitais da Universidade de Coimbra, Praceta

Mota Pinto, 3000-076 Coimbra, Portugal

Full list of author information is available at the end of the article
}

measured by response criteria, but the remaining inflammatory activity (status) seems decisive: 'It is good to feel better but it is better to feel good' [1]. Aletaha and colleagues [2] have demonstrated, in a pooled analysis based on data from several clinical trials in RA involving anti-tumor necrosis factor (anti-TNF), that within the ACR50 (American College of Rheumatology 50\% improvement criteria) and ACR70 responder groups, the most important determinant of progression is the final disease state and not the relative degree of improvement. In fact, functional ability was best and radiographic progression was lowest in patients who had attained disease remission at 1 year compared with those who had attained only low or moderate disease activity. Furthermore, among patients attaining the same disease activity category, physical function and radiographic progression did not differ significantly by the level of response. Even with low disease activity, damage progresses and only sustained remission is capable of abrogating progression of joint destruction [3]. Moreover, optimal disease control is associated with less work disability [4], lower mortality rates [5-7], and better quality of life [8,9]. Even if low disease activity is achieved, work productivity, quality of life, and health states are still significantly worse when compared with remission [9]. Remission used to be a 'guiding utopia' but now, thanks to biological therapy, is a very realistic therapeutic objective. Now that we have in our hands a variety of safe and efficacious medications to achieve it, remission should be our goal in every patient with RA and we should try to achieve that goal as soon as possible [10].

\section{Defining remission}

Remission, our elected goal, should be understood as a near-complete suppression of disease activity or an absence of discernable disease activity [11]. Which of the current definitions of remission should we adopt for practice and for evaluation of the efficacy of different treatment regimes? Remission definitions (Table 1) and their differences have been assessed and reviewed in detail [12-17]. As expected, the proportion of patients achieving remission is dependent on how it is defined [17].

Molenaar and colleagues [18] found that some patients in clinical remission, defined according to the modified 


\begin{tabular}{|c|c|c|}
\hline Criteria & Components/Formula & Cut-offs \\
\hline $\begin{array}{l}\text { ARA [19] and modified } \\
\text { ARA }[20,21]\end{array}$ & $\begin{array}{l}\text { No fatigue (used only for ARA, not for modified ARA criteria) } \\
\text { No joint pain by history } \\
\text { No joint tenderness or pain on motion } \\
\text { No soft tissue swelling in joints or tendon sheaths } \\
\text { Morning stiffness for not more than } 15 \text { minutes } \\
\text { ESR of less than } 30 \mathrm{~mm} / \text { hour in women and less than } 20 \mathrm{~mm} / \text { hour in men }\end{array}$ & $\begin{array}{l}5 / 6 \text { for ARA criteria and } 4 / 5 \text { for modified } \\
\text { ARA; } 2 \text { months required }\end{array}$ \\
\hline DAS [20] & {$[0.54 \times \sqrt{ }($ Ritchie $)]+[0.065 \times \mathrm{SJ}(44]+[0.33 \times \ln (\mathrm{ESR})]+[0.0072 \times \mathrm{GH}(\mathrm{mm})]$} & Less than 1.6 \\
\hline DAS28 [21] & {$[0.56 \times \sqrt{ }(\mathrm{TJC} 28)]+[0.28 \times \sqrt{ }(\mathrm{SJC} 28)]+[0.70 \times \ln (\mathrm{ESR})]+[0.014 \times \mathrm{GH}(\mathrm{mm})]$} & Less than 2.6 (less than 2.4 also proposed) [28] \\
\hline SDAl [28] & $\mathrm{SJC} 28+\mathrm{TJC} 28+\mathrm{PGA}(\mathrm{cm})+\mathrm{EGA}(\mathrm{cm})+\mathrm{CRP}(\mathrm{mg} / \mathrm{dL})$ & Not more than 3.3 \\
\hline CDAI [54] & $\mathrm{SJC} 28+\mathrm{TJC} 28+\mathrm{PGA}(\mathrm{cm})+\mathrm{EGA}(\mathrm{cm})$ & Not more than 2.8 \\
\hline
\end{tabular}

ARA, American Rheumatism Association; CDAl, clinical disease activity index; CRP, C-reactive protein; DAS, disease activity score; DAS28, disease activity score with 28-joint assessment; EGA, evaluator global assessment of disease activity; ESR, erythrocyte sedimentation rate; GH, global health by visual analogue scale; In, natural logarithm; PGA, patient global assessment of disease activity; Ritchie, Ritchie articular index; SDAl, simplified disease activity index; SJC28, 28 swollen joint count; SJC44, 44 swollen joint count; TJC28, 28 tender joint count.

American Rheumatism Association (ARA) criteria [1921] or the disease activity score (DAS) criteria [20], still showed radiographic progression during a 2-year followup, although to a lesser extent than patients having an exacerbation. These findings suggest that DAS/disease activity score with 28-joint assessment (DAS28) and ARA remission criteria may actually describe a low disease activity state rather than a true remission state [22]. In recent trials, DAS28 remission rates exceeded ACR70 response rates [23-26], meaning that more patients achieved a state of DAS28 remission than the proportion of patients reaching a decrease of $70 \%$ or higher in tender and swollen joints. However, other reports have suggested that DAS remission is a more strict criterion for remission and that an ACR70 response should not be used as a surrogate for remission [27]. This should not be surprising given that ACR20/ACR50/ACR70 is designed to measure improvement in disease activity, not to define remission. Importantly, some recent reports have suggested that the clinical disease activity index (CDAI) and simplified disease activity index (SDAI) [28] may represent remission criteria that are more stringent than those by the DAS/DAS28 and the modified ARA response criteria because the latter allow for significant residual disease activity [27,29]. Consequently, smaller proportions of patients may be classified as in remission by SDAI and CDAI criteria than by DAS/DAS28 and modified ARA criteria, and this also has an impact on the percentage of patients showing radiological progression and on patients' mean health assessment questionnaire (HAQ) scores [16,30,31]. One limitation of all of these remission definitions (ARA, DAS/DAS28, and CDAI/ SDAI) is that they omit the effects of RA on functional disability and structural joint damage [28].

Owing to these limitations in the definitions of remission and recognizing its importance as a crucial goal in current management of RA, ACR and the European League Against Rheumatism (EULAR) set up a task force to redefine the concept. The main conclusions from the first meeting are that the new remission definition should be strict, based on no or very low disease activity, and should be validated against long-term outcomes, specifically physical function and radiographic progression [14]. Those in remission should have a stable level of joint damage over time and should have less deterioration or more improvement in functional status over time (remission definition should have predictive validity) [14].

It is our opinion that, while we await this new definition, the practicing rheumatologist should do the following:

1. Choose persistent remission as the primary goal for every patient with RA.

2. Always measure disease activity, using any of the available tools (DAS/DAS28, CDAI/SDAI) to guide therapy toward remission (benchmarking).

3. If remission has been achieved, be critical about it. Check whether the patient fulfills available remission criteria and if the patient does, ask yourself whether that is 'true remission' (for example, a very low erythrocyte sedimentation rate [ESR] or very low/ absent number of tender joints may be leading you to categorize the patient in a 'false state of remission'). Also, be critical about other disease states (for example, a patient with chronically elevated acute-phase reactants not related to RA or a patient with RA and fibromyalgia may never fulfill current definitions of remission but may nonetheless be in 'true remission').

4. If the patient is not in 'true' and persistent remission, continue the search for that goal.

The remainder of this paper will discuss data on DAS/ DAS28 remission and ACR70 response rates. 


\section{Do biologics vary in their ability to induce remission?}

It can be expected that $10 \%$ to $30 \%$ of unselected patients with RA will achieve remission (natural history data) [32]. According to current guidelines in most countries, biologics should be considered if patients do not respond to traditional DMARDs, including methotrexate (MTX), during the first few months of treatment [33]. Most clinicians who now face a traditional DMARD failure encounter the problem of selecting among currently approved biological therapies (adalimumab, etanercept, infliximab, abatacept, rituximab, tocilizumab, certolizumab pegol, golimumab, and anakinra).

According to the current methodological paradigm, no formal judgment on the relative merits of drugs can be made in the absence of head-to-head trials. The only published head-to-head trial with biologics had three arms: abatacept, infliximab, and placebo. The relative efficacies of the biologics were similar at 6 months, with significant differences favoring abatacept at 1 year in DAS28, good EULAR response, low disease activity, and health-related quality of life [34]. One additional head-tohead trial recently started recruiting patients to be randomly assigned to tocilizumab or adalimumab and we are looking forward to the results [35]. Other trials of this kind are lacking and would be welcome. While waiting for more information from clinical trials, the clinician still needs to make a decision. How?

Looking independently at individual trials is not very informative. ACR20, ACR50, and ACR70 response rates in randomized trials are not very different between different drugs, and a crude analysis is not elucidative. Several aspects, including differences in placebo response rates, trial designs, inclusion and exclusion criteria, and safety profile, should be taken into account. In the absence of any evidence of relevant differences between biologics, the clinician may leave the choice to the patient, allowing convenience of administration, access to medication, and safety concerns to serve as guides.

Indirect comparisons produced through formal statistical methodologies have been proposed in an attempt to help clinicians make a choice. We could find three such analyses. Singh and colleagues [36] systematically reviewed the existing updated Cochrane systematic reviews of six biologic DMARDs for RA (abatacept, adalimumab, etanercept, infliximab, rituximab, and anakinra). This review included biologic DMARDs alone used in standard approved doses or in combination with other biologic/traditional DMARDs compared with placebo alone or with placebo plus biologic/traditional DMARDs. The authors anticipated that the observed 'control event rate' (that is, the placebo effect) and the trial duration would be important effect modifiers and adjusted for these factors in the analysis (Table 2). Following this methodology, five biologics (abatacept, adalimumab, etanercept, infliximab, and rituximab) showed significant superiority to placebo but did not differ among themselves. A summary of statistics is presented for the main efficacy outcome of the study, ACR50, as a global 'number needed to treat' (NNT) to benefit from each drug: abatacept NNT $=5$ (95\% confidence interval [CI] 3 to 10$)$, adalimumab NNT $=4$ (95\% CI 3 to 6$)$, etanercept $\mathrm{NNT}=3(95 \%$ CI 3 to 5), infliximab NNT $=5$ (95\% CI 3 to 18$)$, and rituximab NNT $=4(95 \%$ CI 3 to 8$)$.

Bergman and colleagues [37] conducted a mixedtreatment comparison of biologic DMARD efficacy at 24 weeks, among traditional DMARD inadequate responders, in order to make treatment-to-treatment comparisons. This analysis included data from tocilizumab trials, and besides establishing comparisons with placebo, the authors further estimated the efficacy of tocilizumab in comparison with other biologics (anti-TNF being considered a block). A significant difference was found between all biologic DMARDs and placebo in the three outcomes (ACR20, ACR50, and ACR70) (Table 3). Relative risks (RRs) compared with placebo were similar for ACR20, but for ACR50 and especially ACR70, tocilizumab had a higher probability of response than other biologic DMARDs. Tocilizumab had an efficacy similar to that of other biologic DMARDs for ACR20 and ACR50 responses, but a significantly higher ACR70 response compared with TNF- $\alpha$ inhibitors (RR 1.8, 97.5\% CI 1.2 to 2.6) and abatacept (RR 2.0, 97.5\% CI 1.3 to 3.1) (Table 3).

Gartlehner and colleagues [38] also performed a metaanalysis and indirect comparisons between biologics in populations that had residual disease activity despite MTX treatment (that is, excluded MTX-naïve patients), but only the three anti-TNF treatments were included, and no significant differences were found.

These comparisons lack sufficient data on remission because not all of the randomized controlled trials (RCTs) provide that information. Consequently, the most ambitious outcome one can derive from these studies is ACR70. Overall, the abovementioned studies suggest that the efficacies of different biologics regarding this endpoint are very similar. The only exception seems to be a higher response rate, for ACR70, for tocilizumab (antiTNFs being considered together). Notably, however, whether or not a patient will experience an ACR70 response is dependent not only on the efficacy of the intervention but also on the baseline level of disease activity, and this duality makes ACR70 responses tricky for indirect comparisons.

With respect to radiographic progression, a comparison between biologics is more difficult because of the heterogeneity of the methodology applied, but in general, all biologic drugs have shown the potential of successfully inhibiting structural damage progression. 
Table 2. Biologics combined 3-, 6-, and 12-month outcome data (ACR20/ACR50/ACR70), adjusted for control event rate

\begin{tabular}{lc}
\hline & $\begin{array}{c}\text { Combined 3-, 6-, and 12-month outcome data: } \\
\text { relative risk (95\% confidence interval) versus placebo }\end{array}$ \\
\hline ACR20 & $1.72(1.38$ to 2.15$)$ \\
Abatacept & $2.08(1.71$ to 2.52$)$ \\
Adalimumab & $2.09(1.58$ to 2.77$)$ \\
Etanercept & $1.71(1.23$ to 2.38$)$ \\
Infliximab & $1.93(1.40$ to 2.56$)$ \\
Rituximab & \\
ACR50 & $2.29(1.62$ to 3.24$)$ \\
Abatacept & $3.05(2.29$ to 4.07$)$ \\
Adalimumab & $2.93(1.94$ to 4.44$)$ \\
Etanercept & $2.16(1.36$ to 3.41$)$ \\
Infliximab & $2.92(1.76$ to 4.83$)$ \\
Rituximab & \\
ACR70 & $3.40(2.10$ to 4.94$)$ \\
Abatacept & $4.01(2.71$ to 5.92$)$ \\
Adalimumab & $3.02(1.94$ to 4.70$)$ \\
Etanercept & $2.49(1.47$ to 4.24$)$ \\
Infliximab & $4.48(2.12$ to 9.45$)$ \\
Rituximab &
\end{tabular}

Data extracted from Singh and colleagues [36]. ACR20, American College of Rheumatology $20 \%$ improvement criteria; ACR50, American College of Rheumatology $50 \%$ improvement criteria; ACR70, American College of Rheumatology 70\% improvement criteria.

Can the physician, having reviewed these data, distinguish biologics on the basis of published evidence for efficacy? These indirect analyses look promising and are very appealing to the reader but actually have a number of methodological drawbacks, and therefore findings need to be interpreted with caution. What indirect comparisons actually do is adjust for the placebo response across trials under the assumption that the placebo response is a generic reflection of the characteristics of the study population without active intervention. A second assumption is that there is a clear and linear relationship between the placebo response and the response in the active treatment group. In the 2010 EULAR recommendations for the management of RA [39], the expert team deliberately refrained from including these indirect comparisons. Having reviewed the literature systematically, the authors concluded that it was impossible to prioritize the several biologics.

\section{Can biologics be distinguished on the basis of safety?}

Singh and colleagues [36] evaluated withdrawals due to adverse events and concluded that, compared with
Table 3. Relative treatment effect for ACR20/ACR50/ACR70 responses in DMARD-IR patients

\begin{tabular}{|c|c|c|}
\hline & $\begin{array}{c}\text { Biologic DMARD } \\
\text { versus } \\
\text { placebo: } \\
\text { relative } \\
\text { risk }(97.5 \% \mathrm{Cl})\end{array}$ & $\begin{array}{c}\text { Tocilizumab } \\
\text { versus } \\
\text { alternative } \\
\text { biologic } \\
\text { DMARDs: } \\
\text { relative } \\
\text { risk }(97.5 \% \mathrm{Cl})\end{array}$ \\
\hline \multicolumn{3}{|c|}{ ACR20 (random-effects model)a } \\
\hline Tocilizumab & 2.1 (1.6 to 2.5$)$ & 1 \\
\hline TNF-a inhibitors & $2.0(1.7$ to 2.3$)$ & 1.1 (0.8 to 1.3$)$ \\
\hline Abatacept & 1.9 (1.4 to 2.3$)$ & 1.1 (0.8 to 1.6$)$ \\
\hline Rituximab & 1.9 (1.3 to 2.5$)$ & $1.1(0.8$ to 1.7$)$ \\
\hline \multicolumn{3}{|c|}{ ACR50 (random-effects model) ${ }^{a}$} \\
\hline Tocilizumab & $3.6(2.5$ to 5.0$)$ & 1 \\
\hline TNF-a inhibitors & 3.2 (2.5 to 4.3$)$ & $1.1(0.7$ to 1.6$)$ \\
\hline Abatacept & 2.7 (1.7 to 4.0$)$ & 1.3 (0.8 to 2.3$)$ \\
\hline Rituximab & $2.9(1.5$ to 4.9$)$ & $1.2(0.7$ to 2.5$)$ \\
\hline \multicolumn{3}{|c|}{ ACR70 (fixed-effects model)a } \\
\hline Tocilizumab & 6.8 (4.9 to 9.4$)$ & 1 \\
\hline TNF-a inhibitors & 3.8 (3.1 to 4.8$)$ & $1.8(1.2$ to 2.6$)$ \\
\hline Abatacept & 3.4 (2.5 to 4.8$)$ & $2.0(1.3$ to 3.1$)$ \\
\hline Rituximab & 4.3 (2.2 to 8.9) & $1.6(0.7$ to 3.3$)$ \\
\hline
\end{tabular}

Data extracted from Bergman and colleagues [37]. ${ }^{\text {a }}$ Only the most appropriate estimates, according to the authors, are presented, namely random-effects estimated for ACR20 and ACR50 and fixed-effects estimates for ACR70 responses. ACR20, American College of Rheumatology 20\% improvement criteria; ACR50, American College of Rheumatology $50 \%$ improvement criteria; ACR70, American College of Rheumatology 70\% improvement criteria; Cl, confidence interval; DMARD, disease-modifying antirheumatic drug; DMARDIR, disease-modifying antirheumatic drug-inadequate response; TNF- $a$, tumor necrosis factor-alpha.

patients receiving placebo, those receiving adalimumab and infliximab were at significantly higher risk of withdrawals due to adverse events (odds ratio [OR] ranging from 1.54 to 2.21 ). Patients receiving abatacept, etanercept, and rituximab did not differ significantly from those receiving placebo in this aspect. Indirect comparisons revealed that adalimumab was more likely to lead to withdrawals compared with etanercept (OR 1.89, 95\% CI 1.18 to 3.04) and etanercept was less likely than infliximab (OR 0.37, 95\% CI 0.19 to 0.70 ). The results were also translated into an absolute value, in this case number needed to harm $(\mathrm{NNH})$ : adalimumab $\mathrm{NNH}=39(95 \% \mathrm{CI}$ 19 to 162 ) and infliximab $\mathrm{NNH}=18$ (95\% CI 8 to 72 ). This comparison, unfortunately, does not include tocilizumab, a drug that was shown to have a rate of withdrawals due to adverse events of 5.8 per 100 patientyears, driven mainly by elevated liver enzyme levels, infections, and benign and malignant neoplasms [40]. Additionally, there seem to be differences in the risk of tuberculosis (TB) among different biologics, and this might contribute to the selection of the biological agent, 
especially in countries with a high prevalence of TB. Monoclonal antibodies (that is, infliximab and adalimumab) are known for a higher risk of TB compared with soluble TNF receptor therapy (that is, etanercept) $[41,42]$. Minimal data on TB risk in patients treated with non-TNF biological therapies exist, but to date, this risk seems to be limited [42]. Overall, the safety profile of biologics in long-term registries has been very satisfactory, and it is accepted that differences in safety profile would not warrant a major impact in the selection of medication, given the potential benefits at stake [43].

In summary, the clinician is still faced with considerable difficulty in performing an evidence-based selection of the best possible biologic to add to MTX. At the moment, little evidence of any significant difference between the biologics exists. The clinician will weigh benefits against risks specific to each biologic in addition to considering the common adverse events of all of the biologics [44]. Examples of specific adverse events might be neutropenia, increases in total cholesterol, lipoproteins, and triglycerides associated with tocilizumab $[26,40]$; or progressive multifocal leukoencephalopathy associated with rituximab [45]. Of course, such difficulties would be overcome if the individual response to each biologic could be reliably predicted. This would allow us to hope that we can do better than average.

\section{Can response to individual therapeutic agents be predicted?}

The fact that biologics are quite similar in terms of response rate at the group level does not preclude them from being completely different at the individual level. Evaluation of RCTs is based on averages, and surely the majority of patients will not behave like the average; it may even happen that not a single one will. In a hypothetical scenario in which $20 \%$ of the population responds to one out of five different medications but to none of the others, all five medications would have the same response rate at the group level $(20 \%)$ and be considered indistinguishable. However, this conclusion would be wrong to each and every patient!

In fact, different agents may be effective in different people, and if this concept is applied to the RA therapeutic arsenal, there might be such a thing as a disease primarily responsive to MTX, an anti-TNF biologic, an anti-interleukin-6 (IL-6) biologic, and so on. Different 'sensitivity' to different targeted agents is actually to be expected in a complex multifactorial disease like RA, as a function of the relative dominance of one biological pathway over the others in a particular individual, depending on environmental and genetic factors. It is conceivable that the dominant pathogenic mechanisms (and therefore drug responses) may even vary within a patient in the course of the disease. This concept cannot be proven at the moment, because the data available have been driven essentially by historical opportunity: anti-TNF were the first to become available and for that reason they became first line, and the alternatives used upon their failure. Moreover, current methodological wisdom is based on average responses and subgroup analysis is precluded.

The optimal selection among these medications for an individual patient would require that we be able to identify the subset of patients who would respond better to each drug. In this case, initial treatment could be tailored to the individual and we could aim at shortening the time to onset of effective treatment, improving the cost-benefit and risk-benefit ratios of these agents, and eventually achieving $100 \%$ response rate with minimal toxicity.

Several demographic and clinical characteristics as well as serological biomarkers have been studied as predictors of treatment response. Large-scale genetic and proteome studies are now available and have led to the study of genetic polymorphisms (pharmacogenetics) and screening of large amounts of gene transcripts (transcriptomic analysis of pharmacogenomics) and proteins (proteomic analysis of pharmacogenomics) as candidate biomarkers. Several polymorphisms in genes of MTX transporters and the folic acid and adenosine pathways have been studied for MTX response, whereas for anti-TNF- $\alpha$ response, major histocompatibility complex and Fcreceptor polymorphisms have been the main candidates.

So far, however, no clear-cut relationships between demographic, clinical, biochemical, or genetic factors and RA response to biological therapy have been established [46,47]. This may reflect differences in study design, difficulty in controlling for confounders (such as ethnicity, age, disease duration, concomitant therapy, and smoking), or simply the inadequacy of proposed markers [47-49]. It is likely that sensitivity to therapies depends on a conjunction of factors whose study will require complex models combining genetic and non-genetic factors, as proposed by Wessels and colleagues [50] for predicting the efficacy of MTX monotherapy.

In regard to response to anti-TNF agents, most of the studies performed to date have been small, underpowered, and restricted to the analysis of single candidate genes. The only replicated and validated genetic predictor of anti-TNF response is the $308 \mathrm{G} \rightarrow \mathrm{A}$ single-nucleotide polymorphism in the TNF promoter region, but the amount of variation in response accounted for by this marker is probably modest and was questioned in a recent meta-analysis [51]. It is still unknown whether variation in treatment response is determined by several genes that each have a small effect size or by small numbers of genes with large effect sizes. Authors agree on the need for a large-scale, non-hypothesis-driven 
approach to identify further genetic markers of anti-TNF response [47]. In summary, at present, there is no robust biomarker to allow the prediction of responsiveness of individual patients to each biological agent.

\section{Conclusions}

Now what? How should the practicing rheumatologist select biologics upon failure of MTX or classical DMARD combination? Let us summarize the problem. The need for early introduction and rapid escalation of therapy in a response-driven strategy leaves little room for doubt. There is also little doubt that the physician should treat to target and that the elected target should be remission, unless this is proven impossible. The number of biologics available and their efficacy make this target potentially attainable for every patient. At the moment, there is no way to predict individual response to each of these agents.

\section{How should the clinician proceed?}

In our view, the best strategy in the absence of the ability to predict response to specific biologics consists of trial and error and is based on three main principles: (a) start with an effective agent, (b) move to another effective agent unless persistent remission is achieved with acceptable toxicity, and (c) consider going back to the most effective agent if none of the biologic DMARDs results in remission. We could name this strategy 'cycling for remission. This process could develop at a relatively fast pace, thus avoiding the risk of leaving a patient for too long with ineffective medication. Aletaha and colleagues [52] showed that a patient's response to treatment during the first 3 months of biological therapy determined the level of disease activity at 1 year. So, quite soon after therapy has been started, the clinician can assess the efficacy of each biological agent in controlling disease activity at 1 year.

\section{Where should the clinician start?}

With the currently available evidence, the order in which available biological agents should be used cannot be established on evidence-based grounds. This view is also adopted by the 2010 EULAR recommendations for the management of RA; the authors refrain from taking a position with regard to the preferred biologic drug [39]. We fully agree with this position in general. It will obviously require adaptation according to characteristics and preferences of individual patients, safety concerns, access to medications, and local policies. Etanercept and abatacept may be considered for a higher order of priority if the safety profile is given a higher importance, and the opposite may happen with adalimumab and infliximab. The priority of rituximab may be influenced by rheumatoid factor status since patients with positive rheumatoid factor seem to be the best candidates for rituximab [53]. Approval status of a drug (that is, as first or second line) also influences treatment selection. The individual risk profile of a patient should also be taken into account and balanced with an individual's relative and absolute risk of an adverse event with each biological agent. In many cases, the lack of these data may lead the clinician to make the best clinical judgment. TB prevalence and risk shall also be considered, and when the risk of TB is high, non-TNF inhibitors or etanercept may be preferred over monoclonal antibodies.

The EULAR 2010 recommendations [39] also state that it is 'current practice' to prescribe a TNF blocker first, implying that the newer biologicals (rituximab, abatacept, and tocilizumab) come thereafter. The accumulated experience with anti-TNFs may be invoked to support their use as first line. However, it could be argued that more recent biologics have far more controlled data than the original anti-TNFs. Furthermore, the argument of greater experience will retain face value forever unless the current paradigm is questioned. So, we hope that in the near future the clinician will be provided with data regarding the use of the newer biologics as first line and we can progress to a more evidence-based selection among these agents.

Last but not least, the costs of each must be taken into account while choosing the optimal biological treatment. Costs vary among countries and cannot be easily compared. However, the clinician should keep them in mind, and in the absence of other significant differences in benefit and risks between various treatment options, cost considerations may influence therapeutic choices.

There are still several unmet needs in RA. The search for valid and reliable biological and clinical markers to predict responsiveness to a particular targeted therapy and optimize treatment success for a particular individual must continue. The ideal sequence of use of biologics cannot be clearly established on the basis of available data, but the strategy cannot be based solely on issues of historical opportunity: the main reason why anti-TNFs are considered first line is that they were the first to appear. Dynamic treatment strategies avoiding treatment delay should be compared, with newer biologics started early in the disease course. Switching and rotating among biologics until the best possible option is established for each individual will allow the accumulation of data on their respective efficacies and facilitate crucial studies on predictors of response.

\section{Abbreviations}

ACR, American College of Rheumatology; ACR20, American College of Rheumatology 20\% improvement criteria; ACR50, American College of Rheumatology 50\% improvement criteria; ACR70, American College of Rheumatology 70\% improvement criteria; ARA, American Rheumatism Association; CDAl, clinical disease activity index; $\mathrm{Cl}$, confidence interval; DAS, disease activity score; DAS28, disease activity score with 28-joint assessment; 
DMARD, disease-modifying antirheumatic drug; EULAR, European League Against Rheumatism; MTX, methotrexate; NNH, number needed to harm; NNT, number needed to treat; OR, odds ratio; RA, rheumatoid arthritis; RCT, randomized controlled trial; $R R$, relative risk; SDAl, simplified disease activity index; TB, tuberculosis; TNF, tumor necrosis factor.

\section{Competing interests}

SR and PM declare that they have no competing interests. JAPdS has been involved as an investigator in several trials of several biological agents in RA, including infliximab, etanercept, adalimumab, tocilizumab, and golimumab. JAS has received speaker honoraria from Abbott (Abbott Park, IL, USA); research and travel grants from Allergan (Irvine, CA, USA), Takeda (Osaka, Japan), Savient Pharmaceuticals, Inc. (East Brunswick, NJ, USA), Wyeth (Madison, NJ, USA), and Amgen (Thousand Oaks, CA, USA); and consultant fees from Savient Pharmaceuticals, Inc., Novartis and URL Pharma (Philadelphia, PA, USA). RBL has received speaker honoraria or research support from Abbott, Bristol-Myers Squibb Company (Princeton, NJ, USA), Centocor (Horsham, PA, USA), GlaxoSmithKline (Uxbridge, Middlesex, UK), Merck (Darmstadt, Germany), Pfizer (New York, NY, USA), Roche (Basel, Switzerland), ScheringPlough Corporation (Kenilworth, NJ, USA), UCB (Brussels, Belgium), and Wyeth.

\section{Author details}

'Maastricht University Medical Center, PO Box 5800, 6202 AZ Maastricht, The Netherlands. ${ }^{2}$ School for Public Health and Primary Care (CAPHRI), PO Box 616, 6200 MD Maastricht, The Netherlands. 3Department of Rheumatology, Hospital Garcia de Orta, Av. Prof. Torrado da Silva, 2801- 951 Almada, Portugal. ${ }^{4}$ Department of Rheumatology, Hospitais da Universidade de Coimbra, Praceta Mota pinto, 3000-076 Coimbra, Portugal. ${ }^{5}$ Department of Rheumatology, Leiden University Medical Center, PO Box 9600, 2300 RC Leiden, The Netherlands. ${ }^{6}$ Division of Rheumatology, University of Alabama and Birmingham VA Medical Center, Faculty Office Tower 805B, 510 20th Street South, Birmingham, AL 35294, USA.

\section{Published: 4 November 2010}

\section{References}

1. Dougados M: It's good to feel better but it's better to feel good. J Rheumatol 2005, 32:1-2.

2. Aletaha D, Funovits J, Smolen JS: The importance of reporting disease activity states in rheumatoid arthritis clinical trials. Arthritis Rheum 2008 58:2622-2631

3. Smolen JS, Han C, van der Heijde DM, Emery P, Bathon JM, Keystone E, Maini RN, Kalden JR, Aletaha D, Baker D, Han J, Bala M, St Clair EW; Active-Controlled Study of Patients Receiving Infliximab for the Treatment of Rheumatoid Arthritis of Early Onset (ASPIRE) Study Group: Radiographic changes in rheumatoid arthritis patients attaining different disease activity states with methotrexate monotherapy and infliximab plus methotrexate: the impacts of remission and tumour necrosis factor blockade. Ann Rheum Dis 2009, 68:823-827.

4. Puolakka K, Kautiainen H, Mottonen T, Hannonen P, Korpela M, Hakala M, Jarvinen P, Ahonen J, Forsberg S, Leirisalo-Repo M: Early suppression of disease activity is essential for maintenance of work capacity in patients with recent-onset rheumatoid arthritis: five-year experience from the FIN-RACo trial. Arthritis Rheum 2005, 52:36-41.

5. Krause D, Schleusser B, Herborn G, Rau R: Response to methotrexate treatment is associated with reduced mortality in patients with severe rheumatoid arthritis. Arthritis Rheum 2000, 43:14-21.

6. Choi HK, Hernan MA, Seeger JD, Robins JM, Wolfe F: Methotrexate and mortality in patients with rheumatoid arthritis: a prospective study. Lancet 2002, 359:1173-1177.

7. Jacobsson LT, Turesson C, Nilsson JA, Petersson IF, Lindqvist E, Saxne T, Geborek P: Treatment with TNF blockers and mortality risk in patients with rheumatoid arthritis. Ann Rheum Dis 2007, 66:670-675.

8. van der Kooij SM, de Vries-Bouwstra JK, Goekoop-Ruiterman YP, Ewals JA, Han KH, Hazes JM, Kerstens PJ, Peeters AJ, van Zeben D, Breedveld FC, Huizinga TW, Dijkmans BA, Allaart CF: Patient-reported outcomes in a randomized trial comparing four different treatment strategies in recent-onset rheumatoid arthritis. Arthritis Rheum 2009, 61:4-12.

9. Radner H, Smolen J, Aletaha D: Remission of rheumatoid arthritis: benefits from socioeconomic and quality of life perspectives. Paper presented at: 73rd Annual Scientific Meeting of the American College of Rheumatology;
17-21 October 2009; Philadelphia, PA. Abstract 1382

10. Smolen JS, Aletaha D, Bijlsma JW, Breedveld FC, Boumpas D, Burmester G, Combe B, Cutolo M, de Wit M, Dougados M, Emery P, Gibofsky A, GomezReino JJ, Haraoui B, Kalden J, Keystone EC, Kvien TK, McInnes I, Martin-Mola E, Montecucco C, Schoels M, van der Heijde D; T2T Expert Committee: Treating rheumatoid arthritis to target: recommendations of an international task force. Ann Rheum Dis 2010, 69:631-637.

11. van Riel PL, van Gestel AM: Clinical outcome measures in rheumatoid arthritis. Ann Rheum Dis 2000, 59 Suppl 1:i28-31.

12. Ranganath VK, Khanna D, Paulus HE: ACR remission criteria and response criteria. Clin Exp Rheumato/ 2006, 24:S-14-21.

13. Bergman MJ: Assessing adequate treatment response in patients with rheumatoid arthritis. Clin Ther 2009, 31:1219-1231.

14. van Tuyl LH, Vlad SC, Felson DT, Wells G, Boers M: Defining remission in rheumatoid arthritis: results of an initial American College of Rheumatology/European League Against Rheumatism consensus conference. Arthritis Rheum 2009, 61:704-710.

15. Sesin CA, Bingham CO 3rd: Remission in rheumatoid arthritis: wishful thinking or clinical reality? Semin Arthritis Rheum 2005, 35:185-196.

16. Mierau M, Schoels M, Gonda G, Fuchs J, Aletaha D, Smolen JS: Assessing remission in clinical practice. Rheumatology (Oxford) 2007, 46:975-979.

17. Makinen $\mathrm{H}$, Hannonen $\mathrm{P}$, Sokka T: Definitions of remission for rheumatoid arthritis and review of selected clinical cohorts and randomised clinical trials for the rate of remission. Clin Exp Rheumato/ 2006, 24:S-22-28.

18. Molenaar ET, Voskuyl AE, Dinant HJ, Bezemer PD, Boers M, Dijkmans BA: Progression of radiologic damage in patients with rheumatoid arthritis in clinical remission. Arthritis Rheum 2004, 50:36-42.

19. Pinals RS, Masi AT, Larsen RA: Preliminary criteria for clinical remission in rheumatoid arthritis. Arthritis Rheum 1981, 24:1308-1315.

20. Prevoo ML, van Gestel AM, van THMA, van Rijswijk MH, van de Putte LB, van Riel PL: Remission in a prospective study of patients with rheumatoid arthritis. American Rheumatism Association preliminary remission criteria in relation to the disease activity score. Br J Rheumatol 1996, 35:1101-1105.

21. Fransen J, Creemers MC, Van Riel PL: Remission in rheumatoid arthritis: agreement of the disease activity score (DAS28) with the ARA preliminary remission criteria. Rheumatology (Oxford) 2004, 43:1252-1255.

22. Wells GA, Boers M, Shea B, Brooks PM, Simon LS, Strand CV, Aletaha D, Anderson JJ, Bombardier C, Dougados M, Emery P, Felson DT, Fransen J, Furst DE, Hazes JM, Johnson KR, Kirwan JR, Landewé RB, Lassere MN, Michaud K, Suarez-Almazor M, Silman AJ, Smolen JS, Van der Heijde DM, van Riel PL, Wolfe F, Tugwell PS: Minimal disease activity for rheumatoid arthritis: a preliminary definition. J Rheumatol 2005, 32:2016-2024.

23. van Tuyl LH, Lems WF, Voskuyl AE, Kerstens PJ, Garnero P, Dijkmans BA, Boers $M$ : Tight control and intensified COBRA combination treatment in early rheumatoid arthritis: $90 \%$ remission in a pilot trial. Ann Rheum Dis 2008, 67:1574-1577

24. Emery P, Breedveld FC, Hall S, Durez P, Chang DJ, Robertson D, Singh A, Pedersen RD, Koenig AS, Freundlich B: Comparison of methotrexate monotherapy with a combination of methotrexate and etanercept in active, early, moderate to severe rheumatoid arthritis (COMET): a randomised, double-blind, parallel treatment trial. Lancet 2008, 372:375-382

25. Emery P, Keystone E, Tony HP, Cantagrel A, van Vollenhoven R, Sanchez A, Alecock E, Lee J, Kremer J: IL-6 receptor inhibition with tocilizumab improves treatment outcomes in patients with rheumatoid arthritis refractory to anti-tumour necrosis factor biologicals: results from a 24-week multicentre randomised placebo-controlled trial. Ann Rheum Dis 2008, 67:1516-1523.

26. Smolen JS, Beaulieu A, Rubbert-Roth A, Ramos-Remus C, Rovensky J, Alecock E, Woodworth T, Alten R: Effect of interleukin- 6 receptor inhibition with tocilizumab in patients with rheumatoid arthritis (OPTION study): a double-blind, placebo-controlled, randomised trial. Lancet 2008, 371:987-997.

27. van der Heijde D, Klareskog L, Boers M, Landewe R, Codreanu C, Bolosiu HD, Pedersen R, Fatenejad S: Comparison of different definitions to classify remission and sustained remission: 1 year TEMPO results. Ann Rheum Dis 2005, 64:1582-1587.

28. Aletaha D, Ward MM, Machold KP, Nell VP, Stamm T, Smolen JS: Remission and active disease in rheumatoid arthritis: defining criteria for disease activity states. Arthritis Rheum 2005, 52:2625-2636.

29. Makinen $H$, Kautiainen $H$, Hannonen $P$, Sokka T: Is DAS28 an appropriate tool 
to assess remission in rheumatoid arthritis? Ann Rheum Dis 2005, 64:1410-1413.

30. Khanna D, Oh M, Furst DE, Ranganath V, Gold RH, Sharp JT, Park GS, Keystone EC, Paulus HE: Evaluation of the preliminary definitions of minimal disease activity and remission in an early seropositive rheumatoid arthritis cohort. Arthritis Rheum 2007, 57:440-447.

31. Koevoets R, Klarenbeek NB, van der Heijde DMFM, van Krugten MV, van Schaardenburg D, Dijkmans B, Huizinga TWJ, Kerstens P, Allaart CF: Being in remission or in low disease activity in rheumatoid arthritis: different meaning with the use of different composite scores. Paper presented at: 73rd Annual Scientific Meeting of the American College of Rheumatology; 17-21 October 2009; Philadelphia, PA. Abstract 957.

32. Ollier WE, Harrison B, Symmons D: What is the natural history of rheumatoid arthritis? Best Pract Res Clin Rheumatol 2001, 15:27-48.

33. Combe B, Landewe R, Lukas C, Bolosiu HD, Breedveld F, Dougados M, Emery P, Ferraccioli G, Hazes JM, Klareskog L, Machold K, Martin-Mola E, Nielsen H, Silman A, Smolen J, Yazici H: EULAR recommendations for the management of early arthritis: report of a task force of the European Standing Committee for International Clinical Studies Including Therapeutics (ESCISIT). Ann Rheum Dis 2007, 66:34-45

34. Schiff M, Keiserman M, Codding C, Songcharoen S, Berman A, Nayiager S, Saldate C, Li T, Aranda R, Becker JC, Lin C, Cornet PL, Dougados M: Efficacy and safety of abatacept or infliximab vs placebo in ATTEST: a phase III, multi-centre, randomised, double-blind, placebo-controlled study in patients with rheumatoid arthritis and an inadequate response to methotrexate. Ann Rheum Dis 2008, 67:1096-1103.

35. A study of tocilizumab [RoActemra/Actemra] versus adalimumab in patients with rheumatoid arthritis [http://clinicaltrials.gov/ct2/show/ record/NCT01119859].

36. Singh JA, Christensen R, Wells GA, Suarez-Almazor ME, Buchbinder R, LopezOlivo MA, Tanjong Ghogomu E, Tugwell P: Biologics for rheumatoid arthritis: an overview of Cochrane reviews. Cochrane Database Syst Rev 2009:CD007848

37. Bergman GJ, Hochberg MC, Boers M, Wintfeld N, Kielhorn A, Jansen JP: Indirect comparison of tocilizumab and other biologic agents in patients with rheumatoid arthritis and inadequate response to disease-modifying antirheumatic drugs. Semin Arthritis Rheum 2010, 39:425-441.

38. Gartlehner G, Hansen RA, Jonas BL, Thieda P, Lohr KN: The comparative efficacy and safety of biologics for the treatment of rheumatoid arthritis: a systematic review and metaanalysis. J Rheumato/ 2006, 33:2398-2408.

39. Smolen JS, Landewé R, Breedveld FC, Dougados M, Emery P, Gaujoux-Viala C, Gorter S, Knevel R, Nam J, Schoels M, Aletaha D, Buch M, Gossec L, Huizinga T, Bijlsma JW, Burmester G, Combe B, Cutolo M, Gabay C, Gomez-Reino J, Kouloumas M, Kvien TK, Martin-Mola E, McInnes I, Pavelka K, van Riel P, Scholte M, Scott DL, Sokka T, Valesini G, van Vollenhoven R, Winthrop KL, Wong J, Zink A, van der Heijde D: EULAR recommendations for the management of rheumatoid arthritis with synthetic and biological disease-modifying antirheumatic drugs. Ann Rheum Dis 2010, 69:964-975.

40. van Vollenhoven $R$, Siri D, Furie R, Krasnow J, Alecock E, Alten R: Long-term safety and tolerability of tocilizumab treatment in patients with rheumatoid arthritis and a mean treatment duration of 2.4 years. Paper presented at: 73rd Annual Scientific Meeting of the American College of Rheumatology; 17-21 October 2009; Philadelphia, PA. Abstract 1955.

41. Fonseca JE, Canhão H, Silva C, Miguel C, Mediavilla MJ, Teixeira A, Castelão W, Nero P, Bernardes M, Bernardo A, Mariz E, Godinho F, Santos MJ, Bogas M, Oliveira M, Saavedra MJ, Barcelos A, Cruz M, Santos RA, Maurício L, Rodrigues M, Figueiredo G, Quintal A, Patto JV, Malcata A, da Silva JC, Araújo D, Ventura F, Branco J, Queiroz MV; Grupo de Estudos de Artrite Reumatóide da
Sociedade Portuguesa de Reumatologia: [Tuberculosis in rheumatic patients treated with tumour necrosis factor alpha antagonists: the Portuguese experience]. Acta Reumatol Port 2006, 31:247-253.

42. Nam JL, Winthrop KL, van Vollenhoven RF, Pavelka K, Valesini G, Hensor EM, Worthy G, Landewe R, Smolen JS, Emery P, Buch MH: Current evidence for the management of rheumatoid arthritis with biological diseasemodifying antirheumatic drugs: a systematic literature review informing the EULAR recommendations for the management of RA. Ann Rheum Dis, 69:976-986.

43. Zink A, Askling J, Dixon WG, Klareskog L, Silman AJ, Symmons DP: European biologicals registers: methodology, selected results and perspectives. Ann Rheum Dis 2009, 68:1240-1246.

44. Khraishi M: Comparative overview of safety of the biologics in rheumatoid arthritis. J Rheumato/ Supp/ 2009, 82:25-32.

45. Major EO: Progressive multifocal leukoencephalopathy in patients on immunomodulatory therapies. Annu Rev Med, 61:35-47.

46. Lequerre T, Jouen F, Brazier M, Clayssens S, Klemmer N, Menard JF, Mejjad O, Daragon A, Tron F, Le Loet X, Vittecoq O: Autoantibodies, metalloproteinases and bone markers in rheumatoid arthritis patients are unable to predict their responses to infliximab. Rheumatology (Oxford) 2007, 46:446-453.

47. Bansard C, Lequerre T, Daveau M, Boyer O, Tron F, Salier JP, Vittecoq O, Le-Loet $X$ : Can rheumatoid arthritis responsiveness to methotrexate and biologics be predicted? Rheumatology (Oxford) 2009, 48:1021-1028.

48. Bridges SL Jr.: The genetics of rheumatoid arthritis: influences on susceptibility, severity, and treatment response. Curr Rheumatol Rep 1999, 1:164-171.

49. Bridges SL Jr.: Personalized medicine in rheumatoid arthritis: hopes and challenges. Bull NYU Hosp Jt Dis 2007, 65:174-177.

50. Wessels JA, van der Kooij SM, le Cessie S, Kievit W, Barerra P, Allaart CF, Huizinga TW, Guchelaar HJ: A clinical pharmacogenetic model to predict the efficacy of methotrexate monotherapy in recent-onset rheumatoid arthritis. Arthritis Rheum 2007, 56:1765-1775.

51. Pavy S, Toonen EJ, Miceli-Richard C, Barrera P, van Riel PL, Criswell LA, Mariette X, Coenen MJ: Tumour necrosis factor alpha -308G->A polymorphism is not associated with response to TNFalpha blockers in Caucasian patients with rheumatoid arthritis: systematic review and meta-analysis. Ann Rheum Dis 2010, 69:1022-1028.

52. Aletaha D, Funovits J, Keystone EC, Smolen JS: Disease activity early in the course of treatment predicts response to therapy after one year in rheumatoid arthritis patients. Arthritis Rheum 2007, 56:3226-3235.

53. Quartuccio L, Fabris M, Salvin S, Atzeni F, Saracco M, Benucci M, Cimmino M, Morassi P, Masolini P, Pellerito R, Cutolo M, Puttini PS, De Vita S: Rheumatoid factor positivity rather than anti-CCP positivity, a lower disability and a lower number of anti-TNF agents failed are associated with response to rituximab in rheumatoid arthritis. Rheumatology (Oxford) 2009, 48:1557-1559.

54. Aletaha D, Smolen J: The Simplified Disease Activity Index (SDAI) and the Clinical Disease Activity Index (CDAI): a review of their usefulness and validity in rheumatoid arthritis. Clin Exp Rheumatol 2005, 23:S100-108.

doi:10.1186/ar3149

Cite this article as: Ramiro S, et al:. Applying science in practice: the optimization of biological therapy in rheumatoid arthritis. Arthritis Research \&Therapy 2010, 12:220 